\title{
Study on the Problems and Countermeasures of Building Intelligentization in Building Electrical Application
}

\author{
Tianjin Urban Construction University, Tianjin 300384
}

\section{Introduction}

In recent years, the rapid development of the domestic real estate industry, highrise residential and largescale building after another, the construction of the electrical industry is facing new opportunities for development. With the realization of building low-carbon environmental protection and safety and energy conservation goals put forward, building intelligent to promote the construction of electrical systems has been accepted and recognized by the construction industry. In general, the intelligent building electrical system has been widely used in modern buildings, electrical equipment is a building decoration works, is one of the key to building quality assurance. Therefore, the intelligent in the construction of electrical applications in the problems and countermeasures need to conduct in-depth study, so as to promote the development of modern intelligent building.

1 Building intelligent in the construction of electrical applications in the existing problems

\subsection{Performance issues}

(1) Potential connection design

On the electrical building electrical design of all aspects of electrical personnel often ignore the potential connection design, but the electrical potential connection design and grounding role is similar to the prevention of power failure, electric shock, fire and other issues have a certain degree of role. It can be seen that the electrical connection design of the electrical system is absolutely necessary.

(2) Distribution transformer selection and design

In the whole electrical system work, the transformer is the most efficient, usually about $90 \%$ of other electrical equipment, so the electrical staff in the choice of distribution transformers, to consider the transformer capacity and load. In addition, but also consider the transformer in high-speed operation, the surrounding environment or temperature of its impact, to prevent sudden damage to the transformer.

\subsection{Energy saving problems}

Onthestatus of the development of the electrical industry, the domestic construction industry is committed to the development of new technologies and new energy. So far, wind energy, solar and other new technologies have been widely used in all walks of life, especially intelligent building energy-saving optimization, there is a certain environmental benefit and economic value. Although China's new energy development and the application have been developed, but intelligent building electrical energy-saving technology is still in the embryonic period, there are many problems, such as the lack of electrical safety construction monitoring, has not yet achieved automation of building energy

\begin{abstract}
Modern architecture is a product of national economic, political, historical and technological development, and has certain times and nationalities. With the advance of social intelligent construction, the development of building electrical system is one of the main contents of modern building development. Therefore, how to combine intelligent network technology, multimedia technology, communication technology and modern architecture, realize the automation of building monitoring and the efficient management of information, create a good living environment or working environment for users, and it is the current construction industry concern of the key content. This article on building intelligent in the construction of electrical applications in the existing problems and countermeasures to study, hoping for the development of modern architecture to make a modest contribution.
\end{abstract}

Key words: Modern architecture; intelligent; building electrical system; application; development

Publication on 15th July, 2017

efficiency, coordinated control is not full and effective. All inall, building the intelligent energy-saving design in electrical applications to follow the principles of safety, environmental protection, practicality, but also in line with China's architectural design and related policies and 
norms.

\subsection{Security issues}

\section{(1) Electrical grounding problem}

At present, the electrical grounding problem is one of the main problems of building electrical system. If not a professional intelligent grounding, the entire power system will exist security risks. Such as the construction of overhead cable construction, must be repeated grounding, in order to ensure safety and stability. This is due to the construction of electrical equipment leakage, will affect the overall electrical system security.

\section{(2) Line aging problem}

At present, the outer coating of the wire and cable used in the intelligent building is mostly rubber and plastic, and the long-term exposure to the outside will produce corrosion, even the outer rubber or plastic fall off, the line insulation loss. Especially in the case of wet weather, prone to fire and other disasters. In addition, some non-quality certification of the wire, there are often some security problems.

\section{(3) Building mine problem}

So far, many building electrical personnel still take the traditional method of building mine protection system, but this way is a lack of theoretical basis. For modern intelligent building lightning protection design, we should try to select the metal texture of the mining equipment, and do mine grounding work, in order to achieve the balance within the building to improve the safety of intelligent building properties.

\section{(4) Personnel management issues}

At present, the domestic construction of electrical personnel in the electrical installation and construction experience is a relatively lack of overall construction efficiency is low, the quality is not guaranteed. Although the electrical staff has high technical skills, but its lack of a certain architectural experience, will lead to construction plans and construction drawings do not match.
2 Building intelligent in the construction of electrical applications in the relevant countermeasures

\subsection{Electrical design and protection} measures

\section{(1) Electrical grounding}

In the construction of intelligent electrical applications, electrical grounding in the distribution system plays an important role in the system security and stability of the important guarantee. With the development of the intelligent building, the electrical system has undergone tremendous changes, in which the grounding system is no exception. So far, the common electrical grounding system $\mathrm{TN}$ $\mathrm{S}, \mathrm{TN}-\mathrm{C}$ and TN-CS three.

Among them, TN-S electrical grounding system uses a three-phase five-wire system, that is, three FireWire and neutral line, to protect the ground wire; TN-C electrical grounding system uses a three-phase four-wire system, that is, Neutral line; TN-CS electrical grounding system is composed of the above two systems, the former responsible for electricity into the household, which is responsible for electricity into the home, effectively improving the front of the two systems defects and deficiencies, reducing the construction Cost, and improve system security and stability.

\section{(2) Electrical protection}

Building intelligent to be achieved in the electrical protection function mainly from the exchange of work grounding, safety grounding, DC working grounding, lightning protection grounding, shielding and anti-static grounding these five aspects of the ground resistance should be less than $4 \Omega, 4 \Omega, 4 \Omega, 10 \Omega, 100 \Omega$. AC grounding means that the grounding of the transformer or neutral $(\mathrm{N})$ ground; safety protection grounding means that the electrical equipment is not energized metal parts using metal wire and grounding to connect, but not with the protective grounding wire or neutral connection; DC working grounding refers to the larger cross-sectional area of the copper core insulated wire connected to electronic equipment, so that grounding resistance; lightning protection grounding refers to a series of lightning protection system to prevent lightning from the building electrical system damage; shielding and anti-static grounding is a modern building to prevent electromagnetic interference the best way.

2.2 Technical measures and management measures of building electrical personnel

\section{(1) Technical measures}

First, regular technical testing of electrical personnel, and appropriate disclosure of test results. Second, we must strictly in accordance with the design drawings, if the design changes, subject to the design staff, the construction of the person in charge, the supervision team signed the consent, not the same time, the construction of the construction team to ensure that the quality of the construction team, from the construction site to effectively reduce the risk of construction; Third, the electrical installation works before the need to obtain the relevant quality inspection departments of the permit, the installation of materials to meet the design requirements; Fourth, the electrical installation of the acceptance, always adhere to the strict, high standards of the principle. To strictly check the pipeline steel pipe, electrical equipment, junction boxes, lightning protection devices, etc., to effectively improve the phenomenon of shoddy; Fifth, to ensure that the electrical system integrity, such as whether the drawings meet the design requirements, the price is real and objective whether the documents are complete and so on.

\section{(2) Management measures}

In view of the management of electrical personnel, the construction unit to introduce high-tech talent, pay attention to staff training, to build an effective electrical personnel management system, to some extent to promote the development of the modern intelligent building. All in all, we have a new understanding of the electrical system in the intelligent building of 
the building. The efficient management system of the electrical personnel has a positive effect on the wide application of the intelligent electrical system. With the development of information technology, we must continue to promote the construction of horizontal construction of modern engineering construction, promote international academic exchanges, according to market development rules to improve the management system of electrical personnel, so as to promote the future development of China's intelligent building.

2.3 Standardization of intelligent building system

Perfect intelligent building design should be consistent with the national design units and the construction sector of the relevant policies and regulations and system norms. A building that does not have comfort, practicality, and safety is meaningless. The most basic requirement of an intelligent building is to ensure the safety of personal equipment. Especially for some of the higher investment costs, more intensive staff of intelligent buildings, the security is even more important, should strictly follow the relevant policy norms.

It can be seen that the development of effective and unified building policy norms is necessary, but for the study of the development of intelligent building standards do not need to spend too much manpower, material and financial resources, as long as the existing standard system for a certain consolidation. You can form a relatively complete set of intelligent building system norms for the future development of intelligent building system to provide protection.

\section{Conclusion}

All in all, intelligent building electrical system is the product of the development of science and technology, is the crystallization of modern architecture and information technology integration. With the accelerated pace of urban modernization, many intelligent buildings stand in the sky, the scale of the modern intelligent building continued to expand, the corresponding power system should follow the development. In the foreseeable future, the traditional architecture will become more and more intelligent, which is determined by the inevitability of social progress, building intelligent development prospects immeasurable.

\section{References}

[1] Peng Jinyuan. Intelligent building in the computer science and technology application [J]. Jiangxi Building Materials .2015 (24)

[2] Xu Jing. Intelligent building design $[\mathrm{J}]$. Fire sector (electronic version).2016 (06)

[3] Ping Jian. Intelligent building project management system research [J]. Chinese houses (late).2014 (03)

[4] Dou Yinling. China's intelligent building technology development countermeasures [J]. Jiangxi Building Materials.2014 (06)

[5] Liu Long. Talking about the system integration in the intelligent building [J]. Technology and Enterprise.2013 (02)

[6] Mei Chunyan. Based on intelligent building electrical key technology analysis [J]. Education and Teaching Forum.2013 (14)

[7] Yu Likun. Analysis of modern intelligent building automation control technology application $[\mathrm{J}]$. Information communication.2013 (06)
[8] Liu Hui. Intelligent building engineering supervision research $[\mathrm{J}]$. Technology entrepreneurs.2013 (10)

[9] Liu Xianlei. Intelligent building in the computer science and technology application [J]. Technology wind.2012 (05)

[10] Shi Feng. Discussion on intelligent building construction project management [J]. Technology entrepreneurs.2012 (18)

[11] Cai Lu, Sun Duan. Construction cost effective control and research [J]. Jiangxi Building Materials.2016 (01)

[12] Gu Yunjuan. Realistic dilemma and countermeasures analysis of construction cost control $[\mathrm{J}]$. Jiangxi Building Materials.2016 (01)

[13] Huojun Yang, Zhaofeng $\mathrm{Xu}$, Ruibin Xiong, Haorong Li, Tian C.Zhang, Xiaoyu Liu, Denchai Woradechjumroen. Simplational manufacturers' data in unitary HVAC equipment through a DX cooling coil modeling [J]. Energy \& Buildings.2014

[14] José A.Oliveira-Lima, Vasco Delgado-Gomes, Jo? O F.Martins, Celson Lima. Standard-Based Service-Oriented Infrastructure To Integrate Intelligent Buildings In Distributed Generation And Smart Grids [J]. Energy \& Buildings.2014

[15] Bohumír Garlík, Milo? K? Iv. Renewable Energy Unit Commitment, With Different Acceptance of Balanced Power, Solved By Simulated Annealing [J]. Energy \& Buildings. 2013

[16] Zheng Zeng, Rongxiang Zhao, Huan Yang. Micro-Sources Design Of An Intelligent Building Integrated With Micro-Grid [J]. Energy \& Buildings.2013 